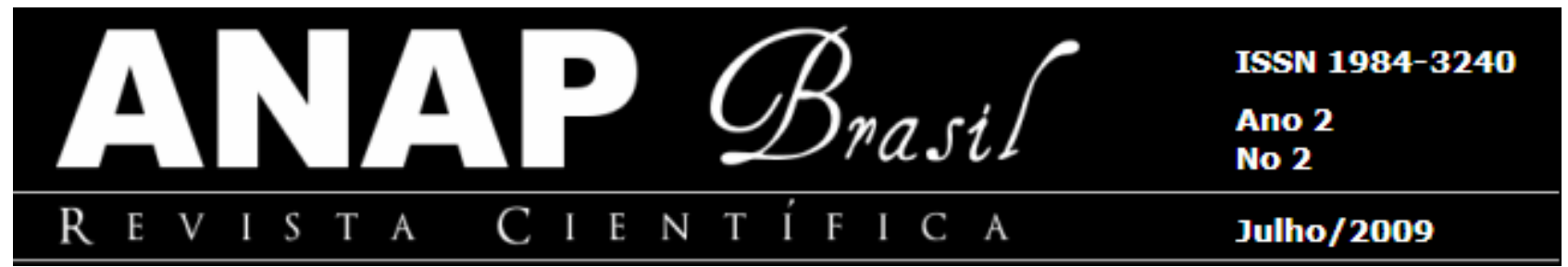

\title{
ECOLUDUS - A CAMINHO DA MATA CILIAR: A PRODUÇÃO DE UM JOGO PARA ABORDAGEM SOBRE A SUCESSÃO ECOLÓGICA NA MATA CILIAR.
}

Daniele Cristina de Souza ${ }^{1}$

Antônio Fernandes Nascimento Júnior²

RESUMO: Um dos problemas ambientais da região oeste paranaense é a degradação das Matas ciliares, sabemos que órgãos responsáveis estão trabalhando para que haja a recomposição desses ecossistemas, mas é primordial o envolvimento da população local. Neste contexto atividades de Educação Ambiental (EA) que esclareçam aspectos da sucessão ecológica das matas ciliares são consideradas importantes para participação mais efetiva e coerente. Sendo aqui apresentada a produção de um jogo como um recurso didático-pedagógico, denominado "Ecoludus: A caminho da Mata ciliar", composto por elementos locais que permitem a familiarização com o tema e dependendo da proposta do educador o aprofundamento nos conceitos apresentados.

Palavras-chave: Jogo e divulgação. Sucessão Ecológica. Mata Ciliar

\section{INTRODUÇÃO}

\footnotetext{
${ }^{1}$ Bacharel e Licenciada em Ciências Biológicas, Pós-graduanda em Ensino de Ciências e Educação Matemática da Universidade Estadual de Londrina-PR, danicatbio@yahoo.com.br

2 Professor Assistente Doutor do Programa de Pós-graduação Projeto, Arte e Sociedade da Faculdade de Arquitetura, Arte e Comunicação da Universidade Estadual Paulista campus Bauru. toni nascimento@yahoo.com.br
} 


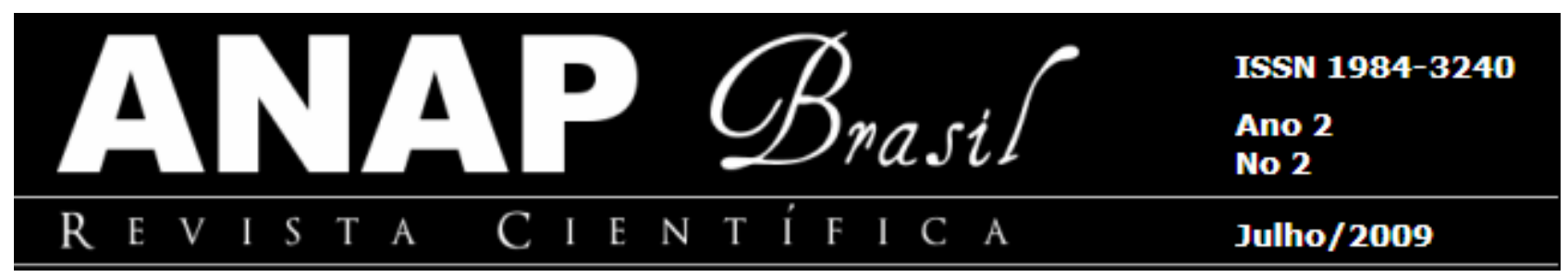

O desenvolvimento do ecossistema envolve mudanças na estrutura de espécies e processos da comunidade ao longo do tempo, quando não há interferências que a interrompam, ocorre de forma bastante previsível (ODUM, 1988). Os ecossistemas característicos das matas ciliares seguem esse princípio, mesmo quando falamos de ambientes reflorestados, havendo neles mudanças na composição de espécies da vegetação durante o seu desenvolvimento, assim como as espécies animais se substituem no sere. Esse conhecimento teórico é essencial para podermos compreender melhor como uma mata ciliar estará se estruturando, para sabermos a importância de cada sere e consequentemente a importância de cada espécie que a compõe.

Tendo em vista esses aspectos, preocupa-se com o conhecimento desses conceitos básicos por parte da comunidade da região oeste do Paraná, principalmente na rede pública de ensino, visto que a degradação das matas ciliares é um dos problemas ambientais enfrentados, fazendo-se necessária a Educação Ambiental (EA).

Para tanto, uma das estratégias na EA é a utilização de materiais e atividades educativas lúdicas que representem ecossistemas locais, como já discutido por Sato (2002) e Souza e Nascimento Júnior $(2005 a, b)$ e mostrado por Santos et al. (2006). Porém pouco material local é encontrado, sendo assim, o objetivo do trabalho foi produzir um jogo que proporcione a abordagem da sucessão ecológica na mata ciliar, visando um material que sirva de recurso para o ensino de ecologia e à EA.

\section{MATERIAIS E MÉTODOS}

Para a elaboração da estrutura do jogo segui-se a metodologia descrita por Souza e Nascimento Júnior (2005b), quanto à forma de abordagem de um tema teórico a partir de jogos que fazem parte da nossa cultura. Assim, o tema central escolhido foi a sucessão ecológica, mais especificamente em relação ao revezamento faunístico (EGLER, 1954 apud ODUM, 1988).

O jogo foi o tradicional jogo de Ludo. A partir de sua estrutura criou-se um tabuleiro e regras que remeta às matas ciliares do Paraná e também os peões (normalmente são pequenos cones coloridos) foram substituídos por miniaturas em 3D, feitas a partir de fotos de quatro espécies de mamíferos característicos da região oeste paranaense: a Capivara (Hidrochoerus hidrochaeris), o Tatu-peludo (Euphractus sexcinthus), o Ratão-do-banhado (Myocastor coypus) e 


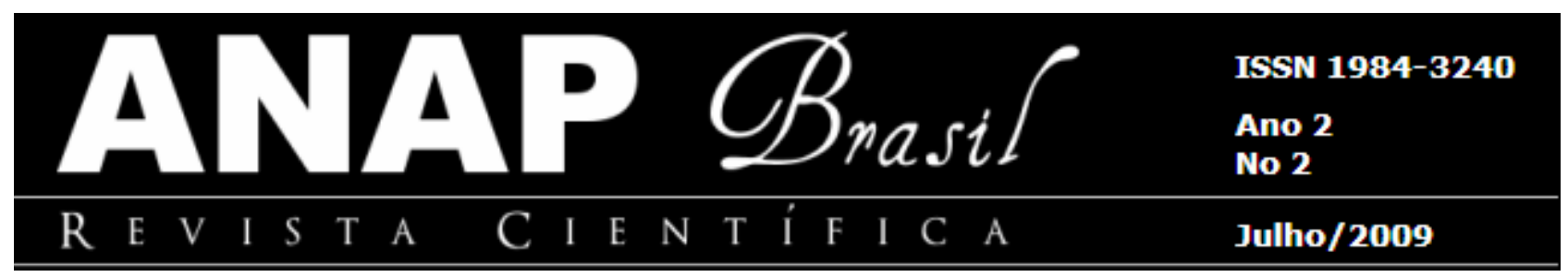

a Cutia (Dasyprocta aguti). A ilustração do tabuleiro foi feita utilizando-se um software editor de imagem, tendo como fundo uma paisagem de Guarapuava-PR. No centro foi usada uma foto da mata ciliar do Rio São Francisco de Toledo-PR, todas fornecidas por Nascimento Júnior.

O tabuleiro foi impresso no formato plotagem em papel cartolina no tamanho de $39 \mathrm{~cm} \mathrm{X}$ $34 \mathrm{~cm}$, sendo revestido com papel plástico transparente do tipo con-tact. Para os peões pegaramse as fotos de animais em perfil produzindo-se outra foto espelho de cada uma delas para que fosse possível fazer os dois lados do animal, apenas para o peão do ratão-do-banhado utilizou-se uma foto que o mostra de frente (figura 2). Seguindo a característica do jogo, que é ter quatro peões para cada cor (azul, vermelho, amarelo e verde), foi impresso em folha de sulfite A4 quatro pares (foto e espelho, exceto para o ratão) de todas as espécies. Foi passado papel con-tact, em seguida montou-se cada peão utilizando-se papel cartão, colando de um lado a foto do animal e do outro sua imagem espelho. Para mantê-los em pé fez-se um suporte em E.V.A (Evenil Venilico acetilico) de $2 \mathrm{~cm} \times 2 \mathrm{~cm}$.

Redigiu-se uma história introdutória do jogo para contextualizar-lo em relação ao tema abordado, juntamente com as regras que foram estabelecidas. O dado foi feito substituindo-se os tradicionais números ou pontos pela face da jaguatirica (Leopardus pardalis), a ilustração foi impressa em folha de sulfite, colado sobre papel cartão e montado no formato de cubo (figura 3).

\section{A DESCRIÇÃO DO JOGO PRODUZIDO E SUA UTILIZAÇÃO}

Como resultado tem-se o protótipo do jogo denominado "ECOLUDUS - À caminho da Mata Ciliar", formado por um tabuleiro (figura 1), 16 peões (figura 2), um dado (figura 3), a história introdutória e as regras do jogo.

\subsection{O JOGO}



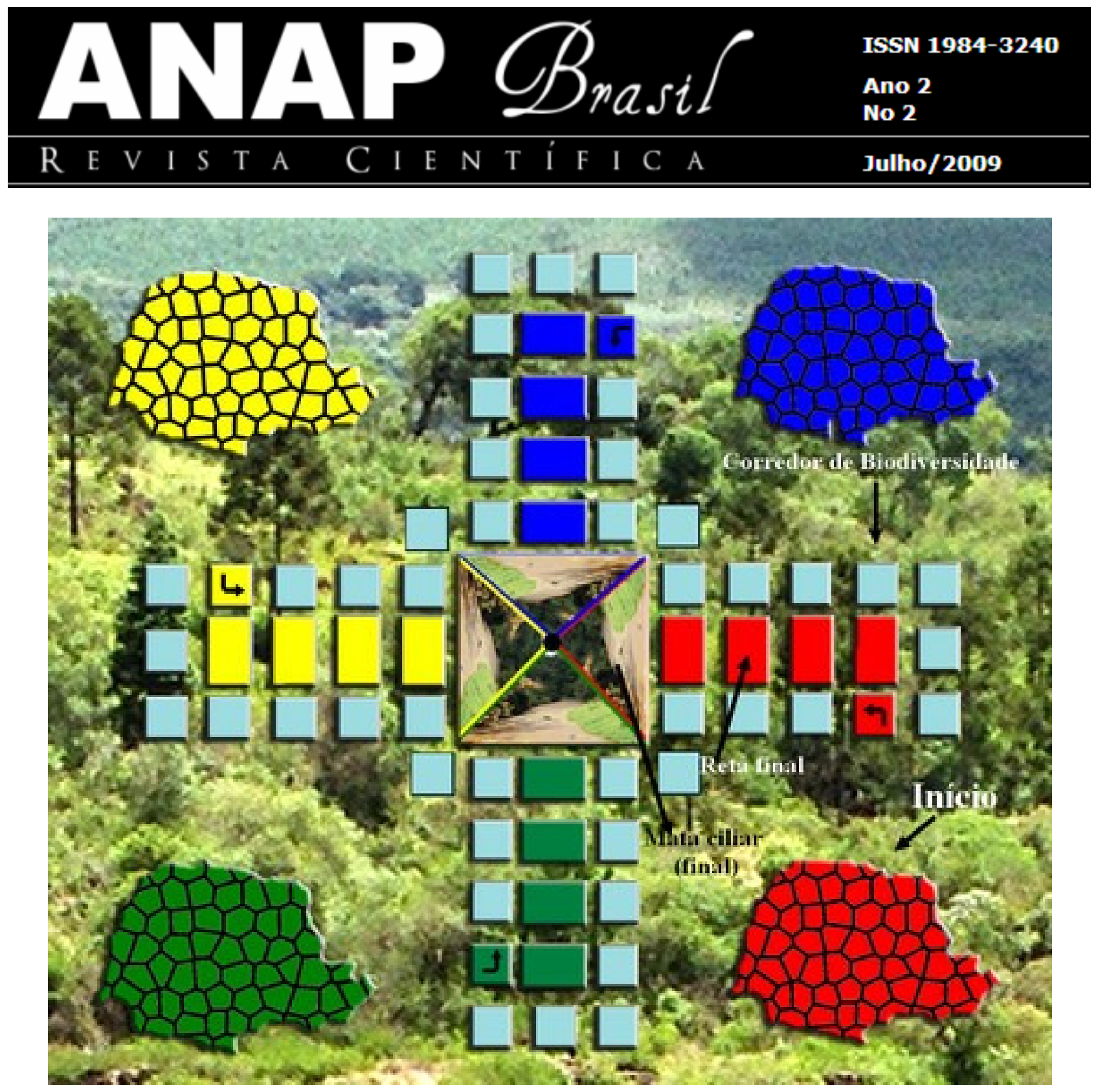

Figura 1 - Tabuleiro do jogo
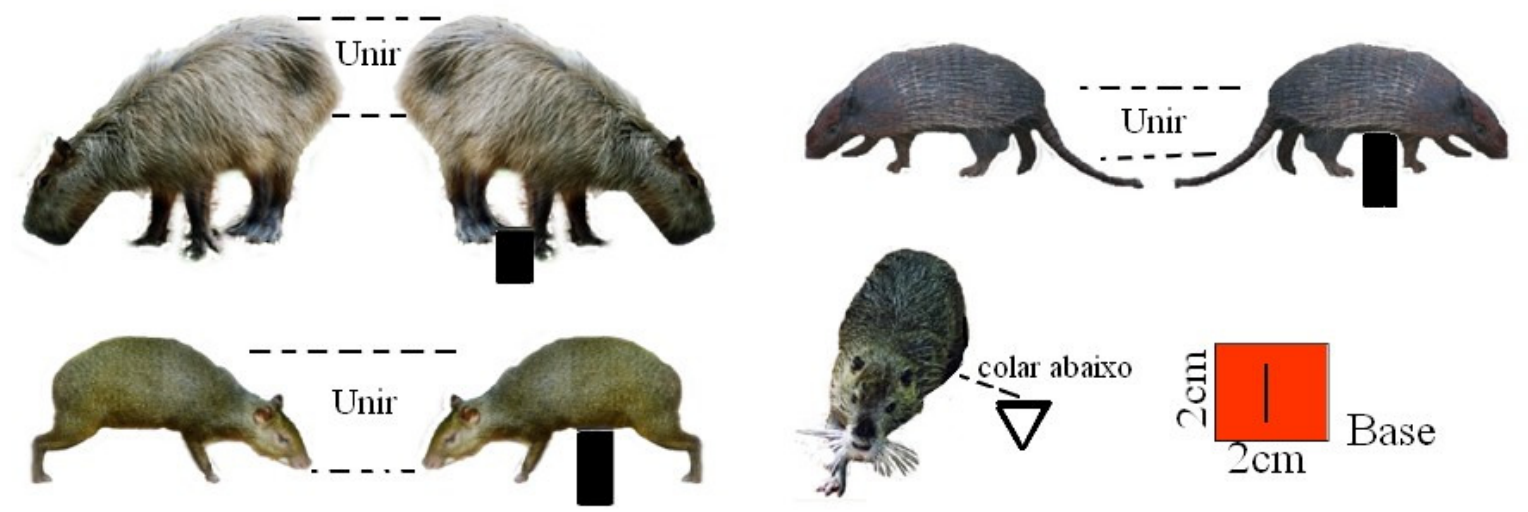

Figura 2 - Estruturas para a montagem dos peões 



Figura 3 - Estrutura para montar o Dado

\subsubsection{História introdutória do jogo EcoLudus}

A mata ciliar do Rio São Francisco está sendo regenerada, sua vegetação está se estruturando, a sucessão ecológica está ocorrendo de forma adequada, para contribuir apenas estão sendo plantadas árvores nativas. As aves e insetos já são visitantes comuns, os peixes respiram mais aliviados, a oxigenação da água está bem melhor, não há tanto detritos lançados no rio, "Ufa" dizem os peixes, mas ainda há muito que melhorar.

A capacidade de suporte populacional do ecossistema está aumentando, até grandes animais estão começando aparecer, afinal agora a mata ciliar está se tornando um local adequado para se viver ou para servir como um caminho seguro para o deslocamento.

Esses animais são espertos, você não acha? Espertos mesmo são a Capivara (Hidrochoerus hidrochaeris), o Tatu-peludo (Euphractus sexcinthus), o Ratão-do-banhado (Myocastor coypus) e a Cutia (Dasyprocta aguti), percebendo que a mata ciliar é um lugar bom para se morar partiram em retirada aproveitando-se dos corredores de biodiversidade para chegar de forma mais segura. Porém, embora sejam da mesma classe, esses mamíferos competem entre si, uma espécie quer ocupar o espaço primeiro que a outra, pois sabe como é, na natureza as coisas não estão fáceis para ninguém. 


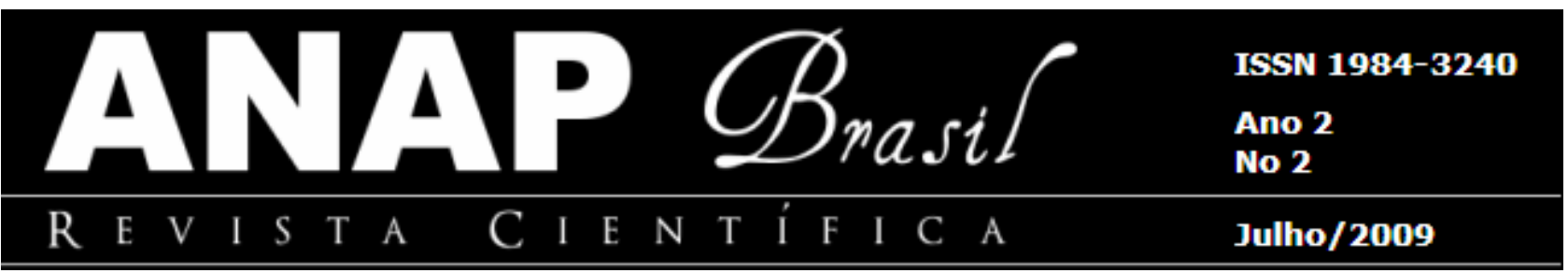

Você quer ajudar esses mamíferos chegar à mata ciliar? Hum... o que você acha? Mas você pode levar só um tipo de população, por isso chame mais alguns amigos para levar as outras populações até lá, e veja quem chegará primeiro.

\subsubsection{Regras}

OBJETIVO: Levar até a mata ciliar os quatro indivíduos (peças) da sua população primeiro que os outros.

1 - Podem jogar de 2 a 4 pessoas, cada um representando uma população diferente. Assim cada jogador é representado por uma espécie diferente, portanto por uma cor diferente.

2- No início as peças ficam sobre o mapa do Paraná referente à sua cor.

3- Cada jogador pode movimentar uma peça de cada vez.

4- Para se movimentar e ficar na casa inicial é necessário jogar o dado e cair 1 ou 6 carinhas da Jaguatirica, caso caia outro nำ passa-se a vez para o competidor.

5- Após sair com a peça na casa inicial anda-se o número de carinhas que o dado mostrar e passa-se o dado para o adversário jogar também.

6- Apenas pode-se jogar o dado mais de uma vez quando cair no lado com 6 carinhas.

7- Caso haja uma peça sua percorrendo o caminho, jogando-se o dado e cair 1 ou 6 pode-se colocar outra peça sua na casa inicial.

8- Se uma peça cair na mesma posição da peça do jogador competidor, ela deve voltar sobre o seu mapa do Paraná e começar de novo.

9- Caso uma peça caia na mesma casa onde está uma peça da própria população ela forma um casal que não permiti que as peças dos competidores passem, formando uma barreira não possibilitando a movimentação. O competidor se movimentará apenas caso o número que caia no dado seja inferior ao número de casas até o casal.

10- O jogador pode desfazer o casal movimentando uma peça por vez. O casal se movimenta junto somente para desmontar um casal competidor, caso isso ocorra todos os indivíduos da população adversária devem voltar ao seu mapa do Paraná e começar de novo.

11- Quando uma peça percorre todas as casas ela entra na reta final correspondente a sua cor. Neste local ela fica protegida dos competidores. A partir deste lugar, para chegar até a mata ciliar é necessário tirar o número exato no dado, caso contrário a peça anda o no de casas somente dentro da reta final até obter o número correto. 


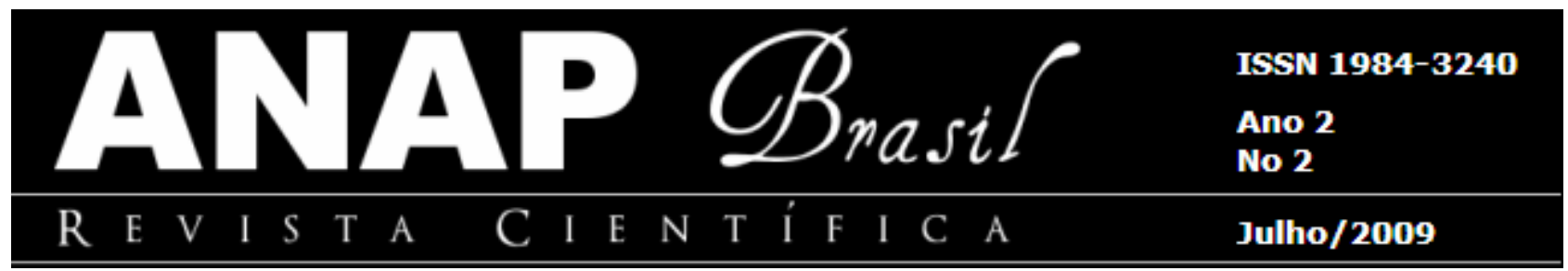

Vence quem levar todos os indivíduos de sua população, atravessando todo o corredor de biodiversidade, entrando na reta final correspondente a cor de sua população e chegando até Mata Ciliar.

\subsection{ASPECTOS PEDAGÓGICOS LEVANTADOS: PENSANDO NA UTILIZAÇÃO DO JOGO}

Ao produzir esse jogo abordando a Sucessão ecológica percebe-se que o conceito foi colocado em evidência, objetivando-se uma melhor compreensão dos processos de desenvolvimento característico do ambiente de mata ciliar, sendo levado em consideração o que discute Teixeira (2006) em torno dos conceitos científicos, de que os mesmos quando abordados devem fazer parte de uma "rede flexível de conhecimentos articulados, um conjunto de informações concatenadas que permitem descrever, prever e explicar as causas dos fenômenos. Cada conceito seria constituído por uma série de outros conceitos" (TEIXEIRA, 2006: p. 125).

O tema Mata ciliar de forma específica está incluída nas Diretrizes Curriculares de Ciências para a Educação Básica do Paraná, no ensino de $5^{\underline{a}}$ a $8^{\underline{a}}$ séries, no conteúdo estruturante "Solo no ecossistema" sendo destacado especificamente como um conhecimento biológico, inicialmente nos parecendo que a discussão sobre a mata ciliar está relacionada apenas com sua importância para a estrutura e composição do solo, entretanto como é destacado no item "Encaminhamento Pedagógico", o professor deve reconhecer que existem conhecimentos físicos, químicos e biológicos no processo pedagógico e que eles devem ser abordados em cada nível de ensino, havendo um integração de conteúdos para se superar a abordagem tradicional, sem haver portanto uma fragmentação de conteúdo como é visto na maioria dos livros didáticos, onde o solo por exemplo é tratado na 5ํㅗirie. (SEED, 2006).

Os conteúdos específicos elencados devem ser tratados ao longo dos quatro anos do Ensino Fundamental, desde que se respeitem o nível cognitivo dos alunos, a realidade local, a diversidade cultural, as diferentes formas de apropriação dos conteúdos específicos por parte dos alunos e que se adote uma linguagem coerente com a faixa etária, para aumentar gradativamente o aprofundamento do estudo. (SEED, 2006, $\mathrm{p}: 45)$

Levando em consideração as informações acima destacadas, o jogo produzido possibilita a abordagem sobre o conceito de sucessão ecológica na Mata ciliar, contudo traz consigo outros conceitos que necessitam ser compreendidos, tais como população, espécie, corredores 


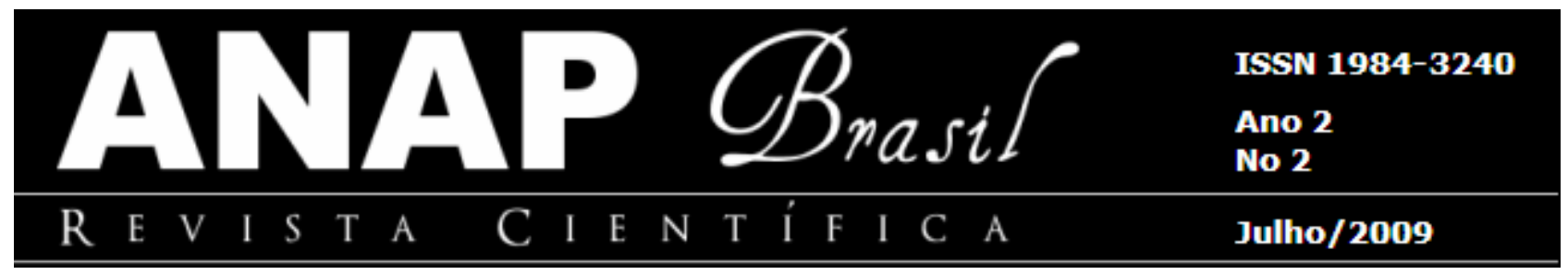

biológicos, capacidade de suporte do ecossistema, relações entre os seres vivos, dentre outros. Assim, ele não é o meio e o fim parar se conseguir uma maior compreensão sobre o tema Mata ciliar, que por sua vez não está apenas relacionado aos aspectos físicos, químicos e biológicos, mas também sociais e econômicos.

Teixeira (2006) levanta alguns papéis do professor quando se considera o conceito científico como redes de conhecimento, para autora:

[...] o professor precisa investigar se os conceitos empregados pelos alunos estão incluindo os invariantes e símbolos vinculados pela explicação causal que ele substantiva, ou se o aluno apenas memorizou termos que ele emprega sem clareza da teoria na qual os conceitos estão emersos. Mas, acima de tudo, é interessante ressaltar que a capacidade de articular a rede de conhecimentos precisa ser estimulada, trabalhada, com toda ênfase. Diálogo, argumentos e apresentação de evidências deveriam ser práticas corriqueiras do cotidiano escolar. (TEIXEIRA, 2006: p. 129)

Dessa forma, ao pensar na utilização do jogo, visa-se que ele remeta a discussão em torno do revezamento faunístico que ocorre no ambiente de mata ciliar, principalmente dos pequenos e médios mamíferos, mas o objetivo de produzi-lo não termina por aí, pois através dele podemos destacar outros questionamentos em torno da temática, sendo um recurso para instigar a atenção do educando e indagá-lo. Algumas questões surgem a partir do jogo: Por que os mamíferos começaram a ocupar a mata ciliar? Quais são as características ambientais que Ihes proporcionam permanecer neste ambiente? Será que somente estes animais são favorecidos pela conservação da mata ciliar? E nós seres humanos o que temos haver com isso? Qual é a relação da população local com as matas ciliares? O texto introdutório do jogo dá algumas pistas, mas os educandos devem ser estimulados a melhor responder essas questões, e outras que surgirem.

\section{CONSIDERAÇÕES FINAIS}

A proposta desse trabalho é que o jogo seja um elemento de familiarização com o tema, e que por meio de sua utilização seja proporcionado um ambiente com estímulos diferenciados das tradicionais abordagens expositivas. Não que essas últimas não sejam importantes, pois pode haver uma associação entre o jogo e as formas expositivas de ensinar, mas considera-se que para se contribuir para a aprendizagem quanto maiores as formas do sujeito entrar em contato com um determinado conhecimento maiores chances ele terá de se apropriar do mesmo, ou ainda 


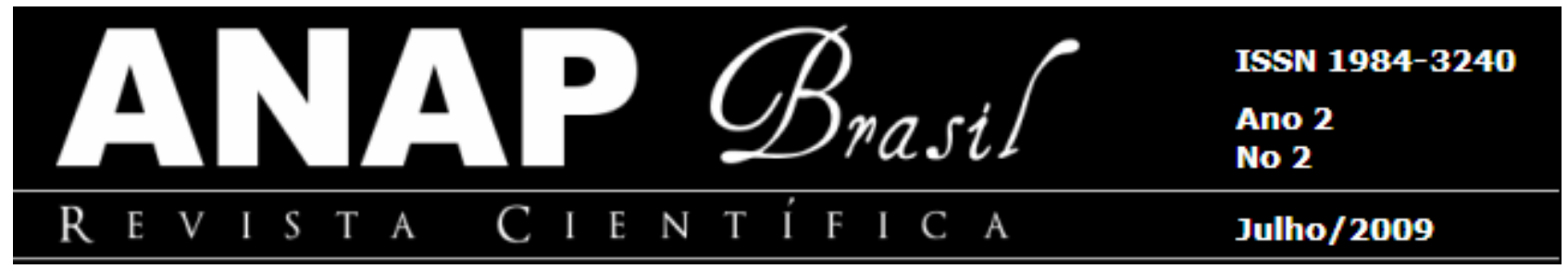

ser levado a compreender outros aspectos a partir de uma ilustração inicial como a encontrada no Ecoludus.

\section{REFERÊNCIAS}

ODUM, E.P. Ecologia. Rio de Janeiro: Guanabara Koogan,1988.

SANTOS, A.A; HECH, R.J.; NASCIMENTO JÚNIOR, A.F. A Educação Ambiental e o jogo estratégico: uma abordagem lúdica na conscientização quanto à importância da mata ciliar no cenário natural. IN: V SIMPÓSIO REGIONAL DE MATA CILIAR. Marechal Cândido Rondon, 2006, p. $15-17$

SATO, M. Educação Ambiental. São Carlos: Rima, 2002.

SEED - Secretaria do Estado de Educação, Governo do Estado do Paraná. Diretrizes

Curriculares de Ciências para a Educação Básica do Paraná. Curitiba, 2006.

SOUZA; D.C. \& NASCIMENTO JÚNIOR, A.F. Jogos ecológicos: uma avaliação de sua utilização como subsídio ao ensino de ecologia e Educação Ambiental. In: III FÓRUM NACIONAL DO MEIO AMBIENTE, Santa Rosa, 2005a. p.133-139

SOUZA; D.C. \& NASCIMENTO JÚNIOR, A.F. Jogos didático-pedagógicos ecológicos: uma proposta para o ensino de Ciências, Ecologia e Educação Ambiental. In: V ENPEC- ENCONTRO NACIONAL DE PESQUISA EM EDUCAÇÃO EM ENSINO DE CIÊNCIAS, Bauru, 2005b p. 1-12

TEIXEIRA, F.M. Fundamentos teóricos que envolvem a concepção de conceitos científicos na construção do conhecimento das Ciências Naturais. Revista Ensaio v.8, no2, dez. 2006, p. 121131 